\title{
UNA COMEDIA VITAL: EL EPISODIO DE ARES y AFRODITA
}

Cilly Müller de Inda

Si bien la epopeya homérica inicia el género trágico, ofrece como contraste, la exteriorización de la vena cómica con todos sus matices.

Aristóteles, en su Poética, especifica con claridad que en Homero se halla el germen de la comedia, por ser el autor de Margites- "imitación dramática de lo ridículo", en cuyo texto perdido no ha logrado abrevar la humanidad posterior al poeta.

Aunque los inicios de la comedia griega resulten imprecisos, por haber sido considerada una creación inferior ${ }^{1}$, es posible ubicar su aparición en el desarrollo de los cantos fálicos, en cuyo transcurso el $\kappa \omega \mu \omega \delta \delta ́ \varsigma$ cantaba en el $\kappa \hat{\omega} \mu \rho \varsigma$ o banquete dionisíaco.

Megara y Sicilia disputan su nacimiento.

En el Ática se introduce en virtud de la libertad de palabra que propicia la democracia $(486 a \text {. C. })^{1}$ y ofrece como apunta Jaeger, "tras lo efimero de sus representaciones, ciertos aspectos eternos del hombre que escapan a la elevación poética de la epopeya y de la tragedia."1

Tragedia y comedia, complementándose, plasman la inclinación humana a la imitación. La primera es inimesis de una praxis encarnada por seres de elevado valor moral y psíquico, que suscita compasión y temor a través de la purificación.

La comedia, en cambio, de acuerdo con la preceptiva de Aristóteles en su Capítulo V, elige "personas de calidad moral o psiquica inferior, no, con todo, según toda clase de vicio, sino respecto de la parte visible de lo que es éticamente bajo o vergonzoso."1 Centra su atención

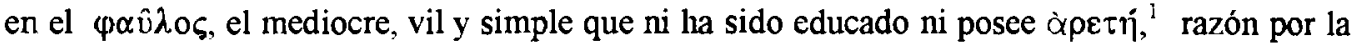

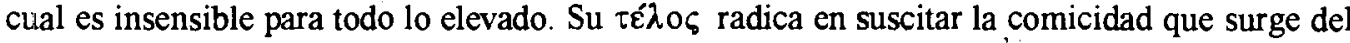
ernpeño en destacar la fealdad o el defecto aunque "sin dolor ni daño."

Se trata, pues, de un sufrimiento limitado, diferente de la $\alpha \mu \alpha \rho \tau i ́ \alpha$ trágica: "error de juicio" en el que cae un inocente en forına inevitable para él o que, por el contrario, es la consecuencia de una negligencia moderadamente culpable. ${ }^{1}$

Concepto de lo cómico: Dificil resulta una definición, pues la preceptiva literaria ni siquiera logra delimitar con exactitud su dominio epistemológico.

Si bien muchos pensadores abordaron con profundidad el tema, como es el caso de Foix ${ }^{l}$ o de Croce ${ }^{1}$, lo centraremos en la perspectiva de Bergson', quien parte de la observación de que lo cómico surge por una inadaptación del individuo frente a la sociedad.

La repetición mecánica de gestos produce comicidad y obliga al cuerpo social a adaptarse a nuevas situaciones que la vida ofrece, haciendo uso del medio correctivo del que dispone: la risa, para evitar la inercia mental y física. Para el filósofo francés, el concepto de lo cómico supera por lo tanto lo puramente estético para equipararse a lo moral y sociológico.

Establece dos condiciones esenciales: a) que se dé dentro del plano humano, puesto que el hombre es el único animal capaz de reír y b) que produzca insensibilidad emocional o

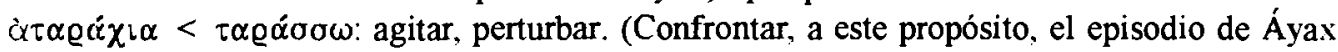
y Odiseo, Ilíada, Canto $\Psi$, v. $773-783$, en el que se ve claramente que el ridículo papel que protagoniza Áyax, cubierto de estiércol, suscita la risa de los argivos porque en ese instante 
logran hacer abstracción de la admiración que suscita su imponente figura para quedarse tan sólo con el impacto visual y ridículo que el ardid de Atenea ha logrado perpetrar a fin de que Odiseo obtenga el premio ansiado).

Episodio de Ares y Afrodita. Odisea, $\Theta$, v.v. 266-366

Conocedor del alma humana, Homero inserta dentro de las tragedias que plasma en su epopeya, pequeñas comedias que logran relajar tensiones. Recordemos el episodio de Tersites ${ }^{1}$ o éste del que nos ocupamos. Obviamos el argumento, por todos conocido, para adentrarnos en la técnica utilizada por el autor para lograr la comicidad.

Mecanismos que el autor emplea:

1) desvalorización de los dioses: Pinta a los inmortales a niłel de los hombres, con sus virtudes y defectos. Con aguda observación, Jaeger considera que: "El hecho de que hasta los altos dioses sean aptos para ser sujetos y objeto de risa cómica demuestra que, en el sentir de los griegos, en todos los hombres y en todos los seres en forma humana reside, al lado de la fuerza que conduce al pathos heroico y a la grave dignidad, la aptitud y la necesidad de la risa."

2) expectativa frustrada: Ares, ${ }^{1}$ cegado por poseer a la bella Afrodita ${ }^{1}$ y amparado en su prepotencia de conquistador vanidoso, menosprecia a Hefestos, quien se burla hábilmente de la ofensa que le inflinge. El engañador, que se ofrece como un triunfador, resulta engañado por alguien reconocido por su torpeza.

3) Contraste entre contrarios: dos parejas opuestas apareden en el texto

a) Ares- Hefestos: El primero es descripto como $\kappa \alpha \lambda$ óc: bello y $\grave{\alpha} \varrho \tau i \pi \phi \varsigma$ : de pies sanos. Ambos epítetos, cargados de intencionalidad, resaltan su perfección física en alusión a la figura grotesca del herrero ingenioso.

Al segundo se lo pinta como $\chi \omega \lambda$ óc: defectuoso, haciendo alusión a sus pies maltrechos y

Resulta evidente que lo disímil de los dos galanes provocara la risa del auditorio.

b)

Hefesto- Afrodita: El primero, según explicita Graves ${ }^{1}$, nació enclenque. mal formado y fue despreciado por su madre Hera. Célebre por su habilidad para trabajar los

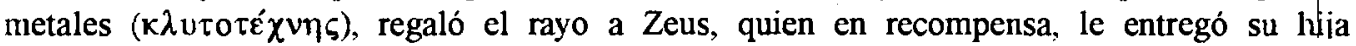
adoptiva, Afrodita.

Afrodita, diosa del anor, la belleza y la fecundidad, encama la antítesis de su deforme marido, siempre tiznado con carbón.

Homero retoma los elementos míticos por todos conocidos pero explota el lado cómilco que la comparación suscita.

4) Lo imprevisto: El ardid del célebre ( $\pi \varepsilon\llcorner\iota \lambda \lambda \cup \tau o ́ \varsigma)$ Hefestos, quien "privado de dones exteriores, poseía los del genio," suscita la risa del coro formado por los expectantes dioses, en señal de admiración incondicional ante la obra de su ingenio creador:

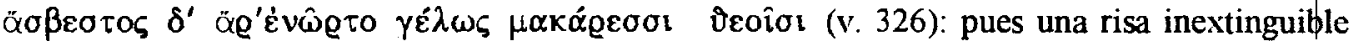


se levantó entre los dichosos dioses. El poeta contrapone la acción del Aoristo del verbo

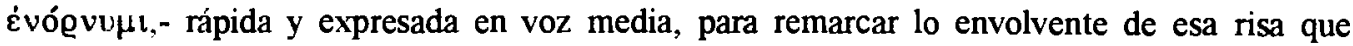

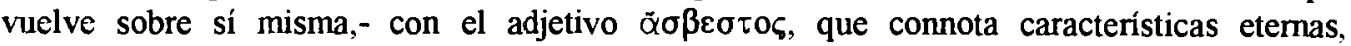
imperecederas.

Planos de la comicidad: Apoyándonos en el agudo estudio que Marta Ofelia P. de De Luca ofrece en Aspectos cómicos en la Ilíada y en la Odisea ${ }^{1}$ marcaremos, a través de la obra de Marcos Victoria, ${ }^{1}$ dos planos de interés:

A) lo cómico objetivo, dentro del cual se ubica lo que es cómico por sí mismo. El poeta logra la comicidad por el sólo hecho de ofrecer personajes o situaciones que la contienen.

B) lo cómico subjetivo: el autor interviene con verdadera voluntad cómica. La perspectiva risueña del sujeto es la que hace surgir la comicidad.

A) Lo cómico objetivo: 1) lo ingenuo: Dentro de esta caracterización ubicamos el episodio de Astianacte, quien, aterrado en brazos de la doncella, no reconoce a su padre, Héctor, que se despide de Andrómaca, cubierta la cabeza con el casco que luce un penacho de crines de caballo que se agitan al viento; ${ }^{1}$

2) la caricatura: Tersites se encuadra en este esquema: personaje con una carga de defectos físicos (cojo, zambo, cabeza puntiaguda, calvo) tiene la osadia de pretender compartir el mundo aristocrático al que no pertenece y cae entonces en üß@ı;

3) lo grotesco: este item, a nuestro entender, excede el límite de lo cómico. Enuncia caracteres enternecedores que lo sitúan en la significación ambivalente del adynaton.

Sin internarnos en el mundo apasionante de esta enigmática figura del lenguaje de la que nos ocupamos en un trabajo anterior, ${ }^{1}$ no queremos dejar de señalar que su presencia revela, siguiendo a Mircea Eliade, "una inextinguible sed ontológica." Homero ofrece seres paradigmáticos en la pintura de Escila, ${ }^{1}$ Caribdis" ${ }^{1}$ o las sirenas devoradoras de hombres. ${ }^{1}$

Los adynata son puentes que impulsan a trascender.

4) lo ridículo: en esta categoría se inscribe, sin lugar a dudas, el episodio de Ares y Afrodita. El mismo Hefesto lo proclama:

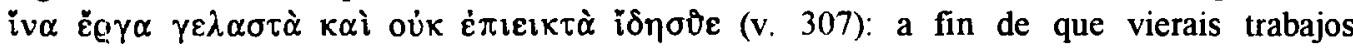
risibles (ridículos) y no convenientes.

Interesante es el uso del verbo ó $\dot{\alpha} \omega$ en Aoristo puntual que exalta la rapidez de la acción de mirar. Los ojos en el mundo griego son vehículos de conocimiento cierto y Hefesto acude a los de sus testigos inmortales para lograr una prueba irrefutable de la acción perversa cometida en perjuicio suyo.

Apuntamos que el verbo ó $\varrho \dot{\alpha} \omega$ : observar, reúne tres raíces: I)wor < vereor (que significa reverenciar, prestar especial atención), ó Q: ver con los ojos del espíritu, usado figuradamente. II) ö $\psi o \mu \alpha \mathbf{~}$ : raíz ò $\pi<\dot{\jmath} \kappa$ : ver, tener ojos (tiene un sentido material, no puede ser usado figuradamente) $<+$ ok: mirada, de ahí deriva el sufijo latino - $\chi \chi$, ocis (ferox, ferocis:

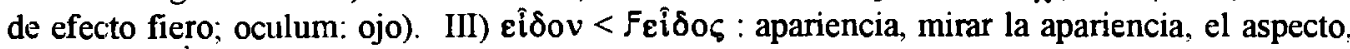
lo que se ve. 
Hefesto, con su deformidad, ingresa la fealdad en el kóouos épico, mundo que retrata no sólo "la excelencia humana sino también la superioridad de seres no humanos $(. .$.$) "1$

Su imupción produce dos efectos opuestos:

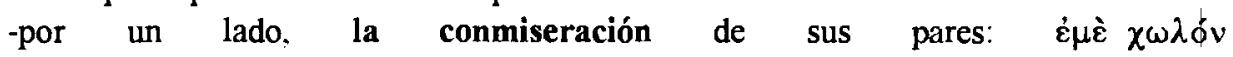

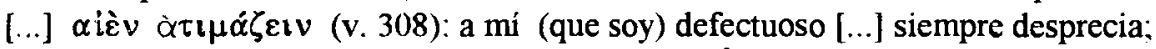

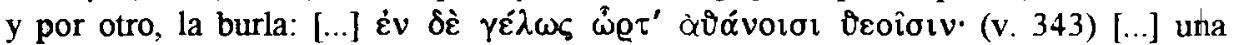
risa se levanto entre los inmortales dioses.

El tono festivo se hace nuevamente presente. Una vez más, lo puntual del Aoristo remarca la rapidez de la acción que se eleva y desvanece.

Importa consignar que "la raíz $\gamma \varepsilon \lambda$-" "idea de luz," consigna el amor del espíritu griego a la claridad y al detalle preciso. El griego se queda con el lado luminoso de las cosas. Ha visto en el rostro humano la misma serenidad o el mismo juego de luz que en el mar: $\gamma \varepsilon \lambda \dot{\varepsilon} \alpha v$ : reír y sonreír es la misma raíz que $\gamma \alpha \lambda \eta \dot{v} v \eta$ : la serenidad tranquila del mar."

En el mundo de la epopeya homérica convive el contraste entre lo trágico y lo luminoso. La ausencia de la luz es la negación de la vida, el mundo tenebroso del Hades.

B) Lo cómico subjetivo: - el chiste: -la conciente actitud de Homero de alimentar la luilaridad, se evidencia en la presencia del chiste, resorte oportuno e intencionado para arrancar la risa de su auditorio.

Apolo y Hermes ${ }^{1}$, encarnan a dos curiosos de la época desinhibidos y aventureros.

Apolo pregunta a Hermes si no se atrevería a soportar las cadenas forjadas por Hefestos, con tal de no privarse del placer de acostarse con Afrodita. Él asiente ufano, aunque lo envolvieran "triple número de inextricables vínculos" y aunque "vosotros (dice), los dioses y aun las diosas todas me estuvierais mirando ${ }^{1 "}$

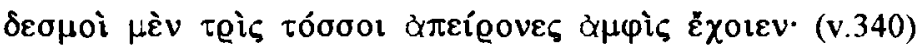

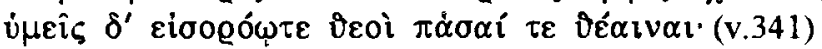

Llama la atención que Hefesto no se indigne ante la mofa de los dioses sino que \$u honor se colma con la promesa formal del pago de la multa por adulterio - $\mu$ oı $\chi \alpha \dot{\alpha} \gamma \varrho \imath \alpha$-, que la ley estipula.'

\section{Conclusión.}

- En Homero hallamos el germen del género cómico, con diversos matices de expresión.

- Su uso intencionado relaja tensiones dramáticas. Es el anticlímax de las tragedias desarrolladas.

- La exageración de caracteres grotescos configura un humor bipolar|y cala hondo en el sentimiento humano.

- La vigencia de Homero, como padre de movimientos literarips posteriores, es innegable. (El desarrollo del tema excede el de este trabajo). 
- "El genial poeta supo equilibrar el tono colosal del epos trágico con los allegro aligeradores de las notas cómicas."

Fieles a la consigna esgrimida en tantos años de docencia, y a fin de acercar a los alumnos al rico manantial del texto homérico, el único que clarifica su cabal comprensión, analizaremos cómo el genial vate apela a diversas formas lingüísticas para enunciar contenidos semánticos que ofrecen distintas connotaciones.

\section{Así: 1) Concepto de "cama- lecho"}

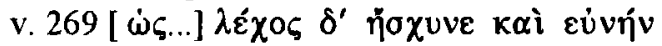

[cómo...] deshonró el lecho nupcial y la cama.

La raíz $\lambda \varepsilon \chi-, \lambda o \chi$ - significa: estar acostado.

De ahí: $\lambda \varepsilon ́ \chi 0 \varsigma$ : lecho nupcial, funerario.

$\lambda \varepsilon ́ \chi \omega:$ acostar.

$\dot{\varepsilon} \lambda \circ \chi \circ \varsigma_{:}$esposa.

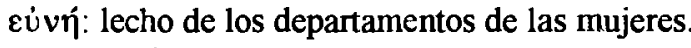

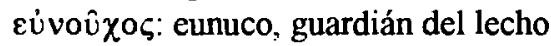

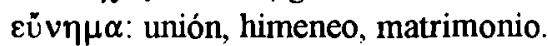

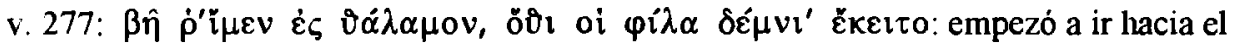
aposento nupcial, en donde yacía el querido lecho.

ป̛ $\alpha \dot{\alpha} \alpha \mu \circ$ \%: aposento, lecho nupcial.

$\delta \varepsilon ́ \mu v i o v:$ especie de colchón; lecho, cama.

Esta última ofrece dos raices: $-\delta \varepsilon \mu \mu \delta \varepsilon \dot{\varepsilon} \mu$ : construir.

De donde: $\delta$ ó $о$ s: casa, templo.

domus-

$-\delta \varepsilon \mu, \delta \circ \mu-, \delta \mu-: \delta \varepsilon \sigma \pi o ́ \tau \eta \xi:$ dueño de casa.

iे $\delta \varepsilon \sigma \pi o \tau i \zeta:$ dueña dominus

domina

dominical

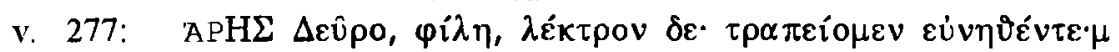
Ares: -ven, querida, al lecho: regocijándonos, acostémonos.

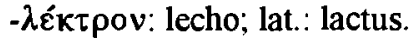

2) Concepto de "palabra" y de "hablar"

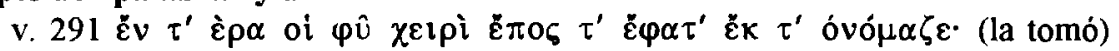
pues, de la mano, hizo salir la palabra, habló (desde) y decía:

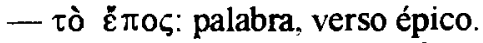

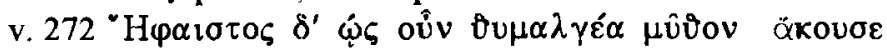

- ó $\mu \hat{v} \theta 0 \varsigma$ : palabra contada, fábula.

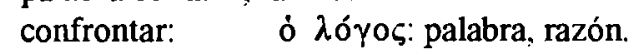


contexto.

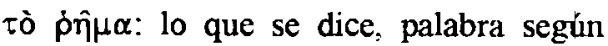

v. 291 Verbos que significan "hablar"

$-\varphi \eta \mu i: \quad{ }^{*} \varphi \eta-, \varphi \omega-, \varphi \alpha-:$ dicción. La misma raíz se encuentra b, n $\varphi \alpha \nu$ - :"hacer ver", "aclarar con palabras."

$\varphi \eta \mu \hat{i}$ : decir, confesar, juzgar.

$\varphi \eta \dot{\mu \eta}$ : palabra, fama, rumor.

- ojvo $\mu \dot{\alpha} \zeta \omega<\dot{o} v a \mu \alpha,-\alpha \tau o \zeta:$ lat. nomen, nombre.

óvo $\mu \alpha ́ \zeta \omega$ : nombrar, llamar por su nombre, denominar.

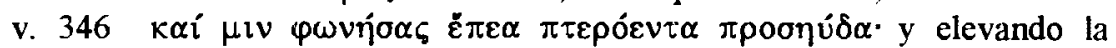
voz para sí, exclamaba aladas palabras.

- $\omega \nu \varepsilon \varepsilon \omega:$ hablar fuerte, elevar la voz, hablar.

Su raiz es la misma de $\varphi \eta \mu i ́$

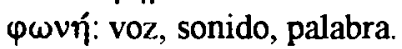

- $\alpha \dot{v} \delta \dot{\alpha} \omega:$ hablar, nombrar, exclamar, dirigir la palabra. $\alpha \dot{\delta} \delta \eta$ : voz humana, palabra.

$\pi \rho \circ \sigma-\alpha \dot{\delta} \delta \dot{\alpha} \omega$ : hablar hacia o para. De donde: dirigir la palabra, hablar.

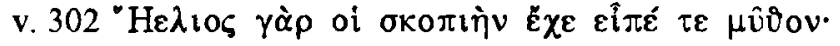
pues el sol tiene un lugar elevado dijo el relato:

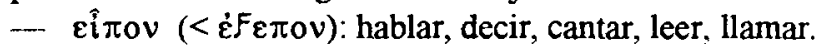

* (F) $\varepsilon \pi-$, (F) ол: hablar.

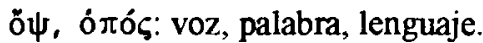

vox, vocis, vocabulum, vocalis, vocatio.

Voco, vocifero, convoco, evoco, provoco, revoco, advocatus. vocal, vocabulario, abogado. ${ }^{1}$

No consideramos agotado el tema. Sólo deseamos que nuestros alumnos abreven en|el sugerente texto de Homero, "el poeta de la inteligencia, el heraldo del Logos."

Las traducciones de los versos homéricos analizados son responsabilidad de la autoral.

\section{Bibliografia Y CITAS.}

${ }^{1}$ ARISTÓTELES. Poética; trad.,prólogo y notas de Francisco de P. Samaranch. Madrid. Aguilar, 1964; Cap. IV, p. 69.

${ }^{1}$ ARISTÓTELES, op. cit., Cap. IV, p. 74.

${ }^{1}$ ARISTÓTELES, op. cit., Cap. IV, p. 74. Nota al pie. 
${ }^{1}$ JAEGER, W. Paideia; trad. Joaquin Xirau; $2^{\text {a }}$ ed. México, F.C.E., 1946. Cap. V, p. 326.

${ }^{1}$ ARISTÓTELES, op. cit., Cap. V, p. 73.

${ }^{1}$ JAEGER, W. , op. cit., Cap. I, p. 21

${ }^{1}$ ARISTÓTELES, op. cit., Cap. V, p. 73.

${ }^{1}$ ARISTÓTELES, op. cit., Cap. XII, p. 101. Nota.

${ }^{1}$ FOIX, JUAN CARLOS. Qué es lo cómico. Bs. As., Columba, 1966.

${ }^{1}$ CROCE, BENEDETTO. Estética como ciencia de la expresión y la lingüística general. Prólogo de Adelchi Attisani, 10ª ed., Bs. As., Nueva Visión, 1962.

' BERGSON, HENRY. La risa. Ensayo sobre sobre la significación de lo cómico. Bs. As., Losada, 1939.

${ }^{1}$ L'Odyssée. "Poésie homérique”. Tome II, chants VIII- XV. Paris, Les Belles Lettres, 1995.

${ }^{1}$ Ilíada, Canto B, 216-219.

${ }^{1}$ JAEGER. W. . op. cit., p.326.

${ }^{1}$ GRAVES, R. Los mitos griegos. Trad. Luis Echávarri. Buenos Aires, Losada, 1967, p. 83.

${ }^{1}$ GRAVES, R. , op. cit., p. 76.

${ }^{1}$ GRAVES, R. , op. cit., p. 98.

${ }^{1}$ DOMINGUEZ de GHIOLDI, DELFINA D.

Diccionario mitológico y Literario. Buenos Aires, 1952, p. 458.

1 PIERO de DE LUCA, MARTA OFELIA. Aspectos cómicos en la Ilíada y en la Odisea. En: Revista de E.E.C.C., U.N.C; Fac. Filosofia y Letras, Inst. Lenguas y Lit. Clásicas, 1993.

DOMÍNGUEZ de GHIOLDI, DELFINA D.

Diccionario mitológico y Literario. Buenos Aires, 1952, p. 458.

${ }^{1}$ VICTORIA, MARCOS. Ensayo Preliminar sobre lo cómico. Buenos Aires, Losada, 1958.

${ }^{1}$ Iliada, Canto Z, v.v. 466-471. 
${ }^{1}$ MÜLLER de INDA, CILLY. El adynaton: Su dimensión trascendente. Longo: Dafnis y Chloé. En: Revista de E.E.C.C., U.N.C; Fac. Filosofia y Letras, Inst. Lenguas y Lit. Clásicas, en prensa.

'ELIADE, M. Lo sagrado y lo profano. Traducc. Luis Gil. Barcelona, Labor, 1970, p.70

'L'Odyssée, op. cit., M, v.v. 73-100.

${ }^{1}$ L'Odyssée, op. cit., M, v.v. 101-110.

${ }^{1}$ L'Odyssée, op. cit., M, v.v. 37-54.

CHANTRAINE, P. Dictionaire étymologique de la langue grecque. Paris, Klincksieck, 1968 , tomo I.

${ }^{1}$ JAEGER, W. , op. cit., Cap. I, p.21.

${ }^{1}$ FONTOYNONT, V. Vocabulario griego. Santander, "Sal terrae", 1962, p. 35, Nota

${ }^{1}$ GRAVES, R. , op. cit., p. 80.

${ }^{1}$ GRAVES, R. , op. cit., p. 71.

'Traducción de Luis Segalá y Estalella de: Homero, Obras completas. Bs. As., "El Ateneo", 1957.

' MIREAUX, EMILE. La vida cotidiana en los tiempos de Homero; trad. Ricardo Anaya. Bs. As., Hachette, 1962, p. 196-97.

' PIERO de DE LUCA, MARTA OFELIA. op. cit., p. 168.

Las etimologías fueron extraídas de: CHANTRAINE, P., op. cit.

FONTOYNONT, V., op. cit.

MENDIZÁBAL, RUFO. Diccionario griego- español y Diccionario mnemónico. España, Razón y Fe, 1963.

${ }^{1}$ MARASSO, ARTURO. Prólogo a: Homero, Obras completas, op. cit., p. 8. 